\title{
PENINGKATAN DERAJAT KESEHATAN ANAK MELALUI PROGRAM PENYULUHAN KESEHATAN GIGI (CARA GOSOK GIGI YANG BENAR) DI PASIRSARI KOTA PEKALONGAN
}

\author{
Improvement Of Children's Health Degree Through The Dental Health Counseling \\ Program (The Correct Dental Method) In Pasirsari, Pekalongan City
}

\author{
Ni'matul Ulya \\ Akademi Kebidanan Harapan Ibu Pekalongan \\ Email : renex_cubby@yahoo.co.id
}

\begin{abstract}
ABSTRAK
Ketepatan menggosok gigi adalah hal terpenting pada perawatan gigi. Menyikat gigi dengan waktu dan cara yang benar sangatlah penting karena gigi dan mulut yang sehat mencerminkan kualitas hidup yang baik. Malas gosok gigi juga dapat menyebabkan penyakit ginggivitis, yaitu peradangan dan pembengkakan gusi yang dapat berakibat infeksi. Data Riskesdas tahun 2018 melaporkan bahwa proporsi masalah gigi dan mulut sebesar 57,6\% dan yang mendapatkan pelayanan dari tenaga medis gigi sebesar $10,2 \%$. Adapun proporsi perilaku menyikat gigi dengan benar sebesar 2,8\%.. Tujuan dari kegiatan ini adalah memberikan pengetahuan dan mengajari anak-anak usia sekolah dasar cara menggosok gigi yang benar di lingkungan Kelurahan Pasirsari Kota Pekalongan. Pada kegiatan ini didapatkan hasil pengetahuan anak-anak sebelum diberikan penyuluhan sebagian besar berpengetahuan cukup sebessar $51,3 \%$ dan setelah diberikan penyuluhan mayoritas mempunyai pengetahuan baik (54\%), dan 70,3\% sudah bisa menggosok gigi dengan cara yang benar. Kegiatan ini diharapkan dapat berlanjut terus dan berkesinambungan di masyarakat, dan petugas kesehatan dapat dengan aktif melakukan pemeriksaan gigi selain di sekolah-sekolah.
\end{abstract}

Kata Kunci : Penyuluhan, Cara Menggosok Gigi yang benar

\begin{abstract}
The accuracy of brushing teeth is the most important thing in dental care. Brushing your teeth at the right time and in the right way is very important because healthy teeth and mouth reflect a good quality of life. Lazy brushing your teeth can also cause gingivitis, which is inflammation and swelling of the gums that can lead to infection. Riskesdas data in 2018 reported that the proportion of dental and oral problems was $57.6 \%$ and those who received services from dental medical personnel were $10.2 \%$. The proportion of correct brushing behavior is $2.8 \%$. The purpose of this activity is to provide knowledge and teach elementary school-aged children how to brush their teeth properly in the Pasirsari Village, Pekalongan City. In this activity, it was found that the knowledge of children before being given counseling was mostly quite knowledgeable by $51.3 \%$ and after being given counseling the majority had good knowledge (54\%), and 70.3\% were able to brush their teeth the right way. It is hoped that this activity will continue and be sustainable in the community, and health workers can actively carry out dental checks other than in schools.
\end{abstract}

Keywords: counseling, the correct way of brushing teeth

\section{PENDAHULUAN}

Kesehatan gigi dan mulut adalah salah satu masalah kesehatan yang membutuhkan penanganan yang berkesinambungan karena memiliki dampak yang sangat luas, sehingga perlu penanganan khusus sebelum terlambat (Dewi, 2017)). Ketepatan menggosok gigi adalah hal terpenting pada perawatan gigi. Menurut data, pemahaman masyarakat dalam memelihara kesehatan gigi masih tergolong rendah.

Kesehatan gigi dan mulut sangat penting karena apabila gigi dan gusi yang rusak dan tidak dirawat bisa menyebabkan rasa sakit, gangguan pada pengunyahan serta dapat mengganggu kesehatan lainnya. Masalah kesehatan gigi dan mulut juga merupakan hal yang sangat penting dalam pembangunan kesehatan, terutama pada 
anak usia sekolah dasar. Usia sekolah dasar merupakan masa yang tepat untuk meletakkan landasan kokoh manusia yang berkualitas, karena kesehatan merupakan faktor penting untuk menentukan kualitas sumber daya manusia.

Menyikat gigi merupakan salah satu kemampuan dasar yang harus dimiliki setiap manusia untuk menjaga kesehatan rongga mulutnya (Sandy, 2016). Menyikat gigi dengan waktu dan cara yang benar sangatlah penting karena gigi dan mulut yang sehat mencerminkan kualitas hidup yang baik (Wahab, 2017). Namun berdasarkan hasil survei nasional Riset Kesehatan Dasar (RISKESDAS) tahun 2018 melaporkan bahwa proporsi masalah gigi dan mulut sebesar $57,6 \%$ dan yang mendapatkan pelayanan dari tenaga medis gigi sebesar 10,2\%. Adapun proporsi perilaku menyikat gigi dengan benar sebesar 2,8\% (Riskesdas, 2018).

Pentingnya perilaku menyikat gigi dengan benar haruslah diajarkan sejak dini, karena perilaku menyikat gigi yang salah akan berdampak terhadap kesehatan gigi dan mulut seseorang, salah satu dampak yang ditimbulkan adalah karies gigi (Wiradona, 2013). Saat ini sekolah-sekolah di Indonesia sudah memberikan pendidikan mengenai cara menyikat gigi melalui program UKGS yang sudah berjalan sejak tahun 1951 (Kemenkes, 2017). Cara yang cermat yang dimaksud adalah menggosok gigi dengan teknik, dan bahan yang tepat. Teknik menggosok gigi harus dapat membersihkan semua permukaan gigi dan gusi, pergerakan sikat tidak boleh merusak jaringan gusi atau menyebabkan abrasi pada gigi, dan menggosok gigi harus memperhatikan sikat gigi dan pasta gigi. Menurut hasil Riset Kesehatan Dasar (RISKESDAS) tahun 2018 menyebutkan bahwa rata-rata penduduk Indonesia anak usia 6-12 tahun bermasalah pada kesehatan gigi dan mulut.

Listiono dalam Dewi (2017), menjelaskan bahwa di Indonesia persentase kebiasaan anak menggosok gigi dengan tepat masih sangat kurang, 94,8\% anak sekolah usia 10-12 tahun memiliki kebiasaan menggosok gigi setiap hari, $73,4 \%$ menggosok gigi setelah makan pagi, dan hanya 26,6\% menggosok gigi sebelum tidur. Prevalensi karies gigi di Indonesia sebesar 81,1 \% pada kelompok usia 3-4 tahun, 92,6\% kelompok usia 5-9 tahun dan $73,4 \%$ di kelompok 10-14 tahun (Riskesdas, 2018).

Pada masa kanak-kanak terkadang kita atau anak kita tidak memperhatikan masalah kesehatan gigi mereka. Mereka makan apa saja tanpa memperhatikan apakah kandungan zat yang ada di dalam makanan itu baik untuk gigi atau tidak, apalagi dengan makanan dan minuman manis. Pengenalan dan perawatan kesehatan gigi anak sejak dini merupakan suatu hal yang kadang-kadang menimbulkan rasa kekhawatiran pada setiap ibu. Kesehatan dan kebersihan rongga mulut yang baik mencerminkan status kesehatan keseluruhan seorang individu. Perilaku, lingkungan, dan pelayanan kesehatan merupakan faktorfaktor yang dapat mempengaruhi status kesehatan gigi dan mulut seseorang. Perilaku memegang peranan penting dalam mempengaruhi status kesehatan gigi dan mulut. Perilaku kesehatan gigi meliputi pengetahuan, sikap dan tindakan yang berkaitan dengan pemeliharaan kesehatan gigi (Narulita, 2016).

\section{METODE}

Kegiatan pengabdian masyarakat ini dilaksanakan di Kelurahan Pasirsari Kota Pekalongan tanggal 9 Februari 2019. Kegiatan ini dilakukan untuk memberikan pengetahuan dan mengajari anak-anak usia sekolah dasar (6-11 tahun) di lingkungan Kelurahan Pasirsari tentang cara menggosok gigi yang benar. Kegiatan ini merupakan kerjasama dengan pihak GREAT (Gerakan Kerelawanan Internasional) Jepang dalam kegiatan pengabdian kepada masyarakat di wilayah Kota Pekalongan. Adapun kegiatan ini dilakukan dengan cara :

1. Anak-anak berkumpul di basecamp pemuda Kelurahan Pasirsari

2. Dilakukan pembukaan oleh pihak GREAT

3. Perkenalan antara pelaksana kegiatan pengmas dengan sasaran 
4. Apersepsi mengenai kesehatan gigi kepada sasaran

5. Pemberian penyuluhan mengenai kesehatan gigi dari penulis dan tim GREAT

6. Tanya jawab seputar materi

7. Demonstrasi cara menggosok gigi yang benar dengan menggunakan phantom gigi

8. Evaluasi kegiatan

9. Praktik satu per satu cara menggosok gigi yang benar

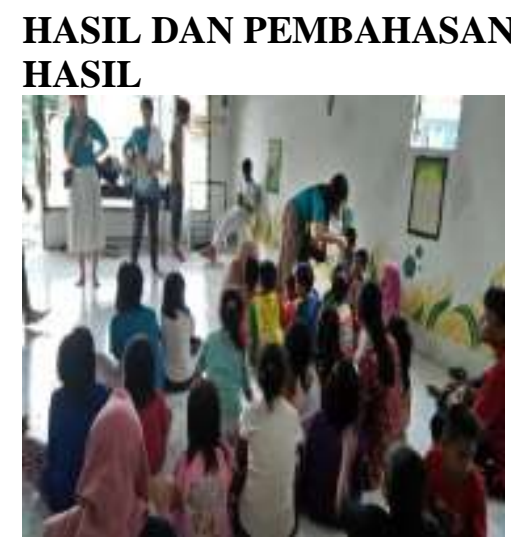

Gambar 1. Proses pemberian edukasi mengenai cara menggosok gigi yang benar

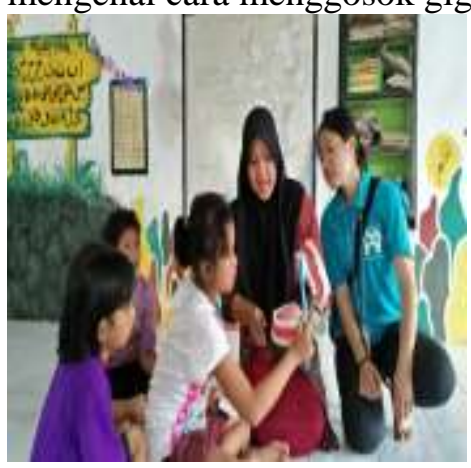

Gambar 2. Praktikum cara gosok gigi yang benar dengan menggunakan phantom gigi

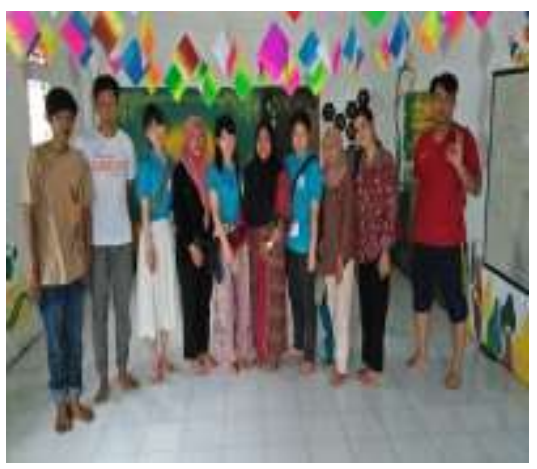

Gambar 3. Foto bersama dengan Tim Great dari Jepang dan Indonesia
Tabel 1. Distribusi Frekuensi Responden Berdasarkan Jenis Kelamin

\begin{tabular}{llcc}
\hline No & Jenis Kelamin & F & $\%$ \\
\hline 1 & Laki-laki & 13 & 35,1 \\
2 & Perempuan & 24 & 64,9 \\
\hline & Total & 37 & 100 \\
\hline
\end{tabular}

Sumber : Data Primer, 2019

Tabel 2. Distribusi Frekuensi Responden Berdasarkan Umur

\begin{tabular}{lccc}
\hline No & Umur & F & $\%$ \\
\hline 1 & $6-8$ tahun & 21 & 56,7 \\
2 & $9-11$ tahun & 16 & 43,3 \\
\hline & Total & 37 & 100 \\
\hline
\end{tabular}

Sumber : Data Primer, 2019

Tabel 3. Pengetahuan Responden Sebelum dan Sesudah kegiatan pengabdian

\begin{tabular}{lllll}
\hline No & Kegiatan & \multicolumn{3}{c}{ Pengetahuan } \\
\cline { 3 - 5 } & & Baik & Cukup & Kurang \\
\hline 1 & $\begin{array}{l}\text { Sebelum } \\
\text { kegiatan }\end{array}$ & $21,6 \%$ & $51,3 \%$ & $27,1 \%$ \\
2 & $\begin{array}{l}\text { Sesudah } \\
\text { Kegiatan }\end{array}$ & $54,0 \%$ & $35,2 \%$ & $10,8 \%$ \\
\hline
\end{tabular}

Sumber : Data Primer, 2019

\section{PEMBAHASAN}

Sasaran kegiatan pengabdian masyarakat ini adalah anak-anak usia sekolah dasar yang berusia 6-11 tahun di lingkungan Kelurahan Pasirsari Kota Pekalongan dengan jumlah 37 orang.

Anak-anak sangat antusias memperhatikan dan mendengarkan pendidikan kesehatan tentang kesehatan gigi. Hal ini dikarenakan materi yang disampaikan menarik dan sesuai kebutuhan para peserta dan dalam kegiatan ini diajarkan (dipraktikkan) cara menggosok gigi yang benar.

Antusiasme peserta sangat tinggi dilihat dari mereka berlomba-lomba (saling berebutan) dalam mempraktekkan cara gosok gigi yang benar. Selain itu, pengetahuan anak-anak juga mengalami peningkatan. Peningkatan pengetahuan mengenai cara gosok gigi yang benar pada anak-anak ini sangat dipengaruhi oleh adanya informasi yang telah mereka dapat melalui kegiatan ini. Selain itu mereka juga diajarkan praktek cara menggosok gigi yang benar sehingga secara tidak langsung 
mereka mempunyai pengalaman cara menggosok gigi yang benar.

Hal ini sesuai dengan teori yang menyatakan bahwa pendidikan kesehatan merupakan kegiatan menyebarkan pesan, menanamkan keyakinan sehingga masyarakat khususnya anak-anak menjadi sadar dan mengerti akan pentingnya menggosok gigi dengan benar (Subargus, 2011) dan sejalan dengan penelitian yang dilakukan oleh Fitriani (2015), bahwa faktor yang mempengaruhi pengetahuan seorang anak diantaranya adanya media massa/informasi dan pengalaman yang terekam di otak anak-anak.

Anak-anak yang mengikuti kegiatan ini merasa sangat senang karena materi yang disampaikan menarik, ada kegiatan prakteknya serta baru pertama kali di lingkungannya ada kegiatan seperti ini. Biasanya anak-anak hanya mendapatkan kegiatan ini di lingkungan sekolah mereka.

\section{KESIMPULAN}

1. Adanya peningkatan pengetahuan anak-anak tentang cara menggosok gigi yang benar yaitu sebelum penyuluhan berpengetahuan cukup $(51,3 \%)$ dan setelah penyuluhan berpengetahuan baik (54\%)

2. Antusiasme anak tinggi yaitu sebanyak $70,3 \%$ anak-anak sudah dapat mempraktekkan cara menggosok gigi yang benar.

\section{DAFTAR PUSTAKA}

Dewi, Wenny Aprilia Roes Patria (2017) Hubungan antara ketepatan menggosok gigi dengan stadium karies gigi pada anak kelas 5 dan 6 di SDN Bulak Rukem 2 Surabaya. Tesis. Universitas Widya Mandala Katholik

Fitriani, N. L., \& Andriyani, S. (2015). Hubungan antara pengetahuan dengan sikap anak usia sekolah akhir (10-12 Tahun) tentang makanan jajanan di SD Negeri II Tagog Apu Padalarang Kabupaten Bandung Barat tahun 2015. Jurnal Pendidikan Keperawatan Indonesia, 1(1), 7-26.

Kemenkes RI. 2017. Profil Kesehatan Indonesia 2016. Kementerian kesehatan Republik Indonesia. Jakarta

Narulita L, Diansari V, Sungkar S. Oral Hygiene Index Simplified (OHI-S) pada Murid Kelas IV SD Negeri 24 Kuta Alam. Journal Caninus Dentistry. 2016; 1(4):6-8

Riset Kesehatan Dasar (2018). Badan Penelitian dan Pengembangan Kesehatan Kementerian RI tahun 2018.

http://www.depkes.go.id/resources/d ownload/infoterkini/materi_rakorpop -20 18/Hasil\%20Riskesdas\%202018.pdf

Sandy, L. P., B. Priyono dan N. Widyanti. 2016. Pengaruh pelatihan menggosok gigi dengan pendekatan Program Pembelajaran Individual (PPI) terhadap peningkatan status kebersihan gigi dan mulut pada anak disabilitas intelektual sedang. Majalah Kedokteran Gigi Indonesia 2 (2).

Subargus, Amin.(2011). Promosi Kesehatan : Melalui Pendidikan Kesehatan Masyarakat . Gosyen Publising, Yogyakarta.

Wahab, S. A., R. Adhani dan Widodo. 2017. Perbandingan Karakteristik Pengguna Gigi Tiruan yang dibuat di Dokter Gigi dengan Tukang Gigi di Banjarmasin. Jurnal Kedokteran Gigi 1 (1).

Wiradona, Irmanita; Widjanarko, Bagoes \& Syamsulhuda. Pengaruh Perilaku Menggosok Gigi terhadap Plak Gigi Pada Siswa Kelas IV dan V di SDN Wilayah Kecamatan Gajahmungkur Semarang. Jurnal Promosi Kesehatan Indonesia, Vol 8 No 1 Januari 2013 